\title{
Los retos de la ciberautopista electrónica en el mundo de la investigación
}

\author{
Challenges posed by the electronic superhighway in the world of research
}

Recibido: 02/09/13 - Aprobado versión final: 25/09/14

Gloria Patricia García Escobar*

\begin{abstract}
Resumen: este trabajo tiene por objetivo mostrar cómo se han tejido algunos entramados sociales, culturales y académicos alrededor de la conformación de una nueva sociedad, la sociedad de la información, mediada por lo informacional y generada principalmente por la aparición de la internet. Destaca el artículo los apuntes de referencia al uso de la web con fines académicos a partir del manejo de los rastreos bibliográficos. Se pretende, además, que los maestros pongan la mirada en algunos principios propios del quehacer docente como son la enseñanza, la puesta en práctica del currículo oculto y el manejo de la didáctica para el uso de la información virtual en el aula.
\end{abstract}

Palabras clave: rastreo bibliográfico, ciberespacio, autopista electrónica, investigación, realidad virtual.

\begin{abstract}
: this work intends to show how some social, cultural and scholar webs have been weaved around the formation of a new society, the information society, which is mediated by information, as a result mainly of internet emergence. The paper highlights some remarks referring to the use of the web for academic purposes in the form of bibliographic tracking. Also, a goal is that faculty look at some principles pertaining to the teaching work, such as teaching itself, the enforcement of hidden curriculum, and didactic tools for the use of online information in the classroom.
\end{abstract}

Keywords: bibliographic tracking, cyberspaces, electronic superhighway, research, virtual reality.

JEL: I21

* Historiadora, Especialista en Gestión de Procesos Curriculares, Magister en Educación - Docencia y docente del Politécnico Colombiano Jaime Isaza Cadavid, Medellín - Colombia.

gpgarcia@elpoli.edu.co 


\section{Contexto Garcia, G.}

\section{Les défis de l'autoroute électronique dans le monde de la recherche}

Résumé: le présent travail se propose de montrer la manière dont se sont développés une série de relations sociales, culturelles et académiques résultant de la conformation d'une nouvelle société traversée par l'information et engendrée notamment par l'apparition d'Internet. Dans cet article nous mettons en relief les annotations de référence à l'utilisation d'Internet à des fins académiques à partir du dépouillement bibliographique. Aussi prétendons-nous d'attirer l'attention des enseignants sur quelques principes essentiels du métier d'enseignant tels que l'enseignement, la mise en œuvre du programme caché et la didactique dans l'utilisation de l'information virtuelle au sein des salles de classe.

Mots clé: dépouillement bibliographique, cyberespace, autoroute électronique, recherche, réalité virtuelle.

\section{Introducción}

La inquietud en el mundo de la investigación por indagar sobre el concepto de vitalidad del rastreo bibliográfico comenzó hace algunos años, a raíz de la cantidad de información que se puede extraer de la ciberautopista, y que en relación con las investigaciones amerita una responsabilidad por parte de los investigadores para revisar la procedencia y autenticidad de la información recopilada.

Este concepto de vitalidad obedece a que en la autopista, si se hace una buena selección, se puede contar con muy buena información para la investigación en el aula; los universitarios de esta generación caminan de la mano con la tecnología, sus aspectos bibliográficos por lo general son traídos de la web, de ahí la importancia de volver vital estos rastreos a través de la mejora en las condiciones de selección y análisis, para que los resultados en la investigación sean muestra de la validez de la información que se mueve en la virtualidad.

También porque ese es el mundo de los jóvenes que día día acompañaron en el aula de clase, en la investigación, y a mí me parece emocionante, porque es como si la comparara con la gran biblioteca de Babilonia o las grandes abadías medievales, donde hasta por los más recónditos lugares se albergaban las grandes obras de la humanidad.

Para escritores como Thomas L. Friedman (2013) la importancia de la ciberautopista es el acceso de muchas personas al mundo virtual, al conocimiento, y con él a la educación; a la posibilidad de encontrar comunidad. Al respecto, en su artículo "El espectacular ascenso de la clase media virtual" hace referencia a que la web ha posibilitado que las persones no solo se comuniquen más ágilmente sino que tengan más conocimiento 
de las cosas y tengan la oportunidad de ver que hay otros con las mismas problemáticas, con quienes pueden formar comunidad.

En la web se observa esa vitalidad que otros medios no la tienen, moverse con rapidez, poder acceder a la información; hace mucho con un blog de información, donde precisamente se inició el debate de esta vitalidad en el rastreo bibliográfico, para enseñar a los estudiantes a revisar con cuidado las fuentes bibliográficas de la web, valorando la riqueza no solo en cantidad sino en calidad, del sinnúmero de libros, revistas, artículos, periódicos, entre otros documentos que se mueven por la autopista.

\section{Un texto motivado por la realidad de ser maestros}

Antes que comenzar con una disertación académica y filosófica de lo que significa ser maestro universitario y de los retos que se tienen en tal ejercicio, como autora de este texto de reflexión quisiera posibilitar la escritura a partir de la primera persona del singular, de tal manera que, conservando la rigurosidad escritural de las revistas científicas, se permita reflejar las intencionalidades del sujeto escritor a partir de sus sensaciones, sus miedos, sus anhelos y sus satisfacciones, a partir de su experiencia personal.

La idea de este artículo ha estado presente en mi quehacer profesional en la docencia y la investigación desde hace varios años, y nuevamente cobra interés con el rastreo para dar respuesta a las preocupaciones derivadas del trabajo de investigación realizado en la Maestría en Educación-Docencia de la Universidad de Manizales. Este artículo se propone como una reflexión frente a las intranquilidades de ser maestras y maestros universitarios, y se apoya principalmente en la metáfora del libro de Bill Gates (1995), "Camino al futuro", no tanto por el contenido del libro, sino por lo expresado en su carátula: un ser humano que representa a muchos otros seres humanos y a una inmensa autopista, la posibilidad de la realidad en tiempo real.

El interés por develar cómo el uso de la autopista electrónica era un elemento vital en los rastreos bibliográficas en la investigación me llevó a poner más atención en su significado, porque allí veía reflejada a mi hija, a sus amigos, a sus compañeros de universidad y a mis estudiantes; ellos caminan todos los días por las realidades que recrean estas autopistas de la información, y por esta razón mi interés en observar cómo mis estudiantes vivían la virtualidad, y cómo desde mi ejercicio docente podría lograr que ellos comprendieran mi gusto por su mundo, sin perder de vista que tal ejercicio ayudaría significativamente a cultivar herramientas de investigación (mi campo de trabajo docente) de otrora, que se contextualizan día a día. 


\section{Contexto Garcia, G.}

\section{¿Por qué el ciberespacio?}

El ciberespacio es ese mundo virtual que me alienta a recontextualizar mi visión de la academia y de las formas de enseñar hoy en los espacios universitarios, ese mundo comparable con el que vio Miranda, la protagonista del maravilloso texto de Shakespeare "La Tempestad", cuando exclama: "Ah, gran mundo nuevo".

El ciberespacio ${ }^{2}$ es un mundo nuevo donde, al igual que en la trama shakesperiana, son muchos los vientos, naufragios y tempestades que lo circundan. Es un concepto difícil de abordar sin la metáfora; sería una lenta caída al vacío de un mundo en el que los seres humanos han construido realidades: el mundo digital.

En "Shakespeare como filosofía", de Cándido Pérez Gallego, se argumenta que con Shakespeare se "creó el performance, se instauró el orden escénico que suplantara la realidad pero que todos aceptaban. Inventó la fantasía de la época, puso nombre a la imaginación" (2003, p. 83). Shakespeare utilizó el cuerpo de los actores de teatro para poner múltiples ideas de época en acción; el ciberespacio utiliza el ordenador y la internet para proponerse como ese nuevo escenario de acción en el que se hace necesario un maestro shakesperiano que también le ponga imaginación al uso de lo que los estudiantes rastrean en la web; sin esta acción, nada tiene sentido para la academia en el uso de la información proveniente de la web.

La primera metáfora fue el espacio, ese del que acabo de hablar; ${ }^{3}$ otra tiene que ver con el tiempo. Bill Gates, en su libro "Camino al futuro" (1995, p. 68), plantea que "[...] uno de los beneficios que proporciona la autopista de la información será el de permitirnos tener más control sobre nuestros horarios [...]", pues es bien importante este aspecto debido a que tradicionalmente, lo que más nos podría atrasar en nuestro desempeño como

1. La trama de La Tempestad hace alusión a una serie de acontecimientos que ocurren en el naufragio que se produce al encallar la embarcación donde viajaban personajes de la nobleza europea; pero lo que me interesa de la relación del texto con la autopista electrónica, es el uso metafórico entre mundos, cómo los personajes en diferentes épocas se asombran frente a lo nuevo que ofrecen los nuevos mundos. En Tempestad, que ha sido considerada una de las últimas obras de Shakespeare, donde el autor se da la oportunidad de mostrarse como filósofo y también como alguien que se permite darle vida y sentir a los personajes, estos se mueven entre el sueño y la realidad. En el ciberespacio ese movimiento se da entre la realidad y la hiperrealidad, y es en esta realidad donde el maestro penetra para reconfigurar los procesos de rastreo de información ante nuevas formas de utilización de este en los espacios académicos.

2. El neologismo 'ciberespacio' (cyberspace) es atribuido a W. Gibson, que lo tendría formulado en Neuromancer (1984), texto en el que el autor realiza toda una poesía épica en torno a la virtualidad a través de la simulación futurista.

3. El espacio de mis estudiantes no es el espacio de la geografía física, a veces tan agreste, incomunicada no solo por la geografía misma sino por las formas de representación de la violencia en los territorios físicos; en ocasiones es difícil moverse en el territorio físico, cargado de palabras como violencia, pobreza, desplazamiento. Mientras que en el mundo del ciberespacio todavía hoy hay mayor libertad de movimiento, y la comunicación fluye muy a pesar del totalitarismo de algunos regímenes en el mundo. Es interesante cuando hablamos de metáforas, porque la autopista electrónica ha eliminado del paisaje la relación con el concepto de distancia, debido a que no importa que estés al lado o muy alejado, la información y la comunicación están ahí, en micro milésimas de segundo. 
estudiantes, maestros, investigadores, entre otros, es el manejo del tiempo. A veces las bibliotecas estaban bastante alejadas de nuestro acceso cotidiano, teníamos poco tiempo para estar en ellas, debíamos recurrir al préstamo de toneladas de textos para leer en poco tiempo, en fin, existían y aún existen muchas otras razones para mostrar lo favorable que es hoy para nosotros la accesibilidad a la información y a la adquisición del conocimiento.

Gates, en otra de sus frases, nos introduce en el placer que produce alcanzar logros, en términos no sólo del acceso a conocer sino al poder hacerlo en tiempos reales, "[...] la autopista nos proporcionará posibilidades que parecen mágicas [...]" (1995, p. 68), infinidad de posibles formas de llegar al conocimiento; para mí, esto constituye un aspecto mágico de la vida académica.

Duele un poco, y en ocasiones es vergonzoso, que pensemos que al descubrir la magia de la autopista, conocer los secretos de Pandora o la magia de Merlín ${ }^{4}$ ya todo está hecho y es suficiente; eso es una falacia, y es este aspecto el que ha puesto a las TIC en una cacería de brujas. ${ }^{5}$ Hay mucho ruido sobre su uso. Se escuchan en los pasillos universitarios comentarios acerca de cómo los seres humanos se han "relajado", no producen conocimiento, copian y pegan lo que encuentran en la internet, entre otros vejámenes a la producción académica y científica universitaria, lo cual dista mucho del sentido ético de ser profesionales en cualquier área del conocimiento.

Y por supuesto hay que reconocer que existen dificultades y que las facilidades que brinda el mundo de nuestra primera metáfora son más atractivas que el hecho mismo de pensar, pero es allí donde los maestros debemos saber cómo mover las fichas, de tal manera que los estudiantes reflexionen y comprendan que el "toque mágico" que soluciona sus problemas académicos no lo constituye el mero uso de la herramienta, y donde entra en juego nuestra responsabilidad como formadores de sujetos, para producir respuestas a las demandas de nuestros estudiantes.

4. Con este lenguaje metafórico quiero que tanto los maestros como los estudiantes pensemos que en los mundos de la virtualidad; en su autopista electrónica; el ciberespacio; la web; la internet, la intranet, son mundos de realidad donde todo puede subsistir y que muy seguramente se pueden encontrar elementos de la información y la comunicación que incomoden a unos y a otros; pero lo importante es que como espacio social puede ser usado por todos; entonces es en el uso donde radica la importancia de este discurso que vengo tejiendo; yo creo que trabajando en el mundo que los estudiantes se mueven, con las destrezas y herramientas pedagógicas de los maestros, se logran los objetivos.

5. El contexto de estas palabras "cacería de brujas", desde la historia y la literatura ha estado marcada en algunos casos por la persecución a quienes pensaban diferente en términos ideológicos; otros por hacer parte de prácticas no permitidas dentro de la religión cristiana, pero puede decirse que para el caso específico que nos ocupa se puede tomar en dos sentidos: una cacería de brujas desde una visión muy conservadora del uso de materiales de rastreo en los que no se incluya la web, y la otra desde una mirada poco objetiva a la hora de desarrollar en el aula actividades que incluyan la información de la web y sea valorado y trabajada en el aula con respeto y reflexión crítica como cualquier otro documento. Tampoco hay que dejar de lado que la mala utilización de la información web ha acarreado problemas como el plagio, que debe ser cuestionado, y aquellos trabajos con plagio deben ser evaluados con rigor; quizás para algunos esto pueda ser una cacería de brujas o como lo que ocurre con las leyes anti plagio o los perseguidos por divulgar información no permitida por algunos Estados, como el caso de Julián Assange de wikilikes por nombrar alguno. 


\section{Contexto Garcia, 6 .}

No basta "copiar" pero también hay una gran responsabilidad de la academia y de los profesores en ese ejercicio perverso, favorito de los estudiantes. Debe haber entonces un compromiso sentido para que nuestros estudiantes utilicen bien las herramientas que los docentes deberán enseñar mediante el acompañamiento en los procesos académicos.

Por tanto, la discusión central de este texto se basa principalmente en la necesidad de comprender las visiones de mundo de nuestros nuevos estudiantes, de aquellos sujetos que mutan sus necesidades, sus pasiones y sus anhelos, sujetos que no se encuentran con nosotros - sus profesores - en los gustos, en las consideraciones e importancias de la vida cotidiana, pero que son aún nuestros estudiantes, y como profesores responsables y éticos tenemos la obligación de comprender esas particularidades, someternos a la crítica y estar en capacidad de abrir nuestras mentes y corazones al cambio de nuestras prácticas pedagógicas y didácticas.

\section{El rastreo bibliográfico: El caso de las ciencias económicas, administrativas y contables}

Quisiera, en primera medida, contextualizar la discusión en términos de la importancia que reviste para mí la investigación social, y particularmente la enseñanza de la investigación en los ámbitos universitarios. Por tanto, quiero concentrarme en el rastreo bibliográfico como herramienta fundamental para el desarrollo de la investigación universitaria, particularmente en ciencias sociales aplicadas, áreas del conocimiento en las cuales he desarrollado gran parte de mi labor docente.

Bill Gates dice: "[...] la autopista de la información hará que sintamos como si se hubiera suprimido toda la maquinaria intermedia entre nosotros y el objeto de nuestro interés" (1995, p. 69). Escogí la anterior frase para hacer algunas conexiones que me parecen vitales respecto a la tarea del ser humano, más allá de los resultados de la herramienta, más allá de copiar y pegar. Ese objeto del que habla Gates, que puede ser cualquier cosa, es el problema sustancial de la investigación que hoy puede desarrollarse a través de una gran búsqueda detectivesca, utilizando la gran autopista; esto se vuelve interesante en el sentido de que, como dice un gran científico colombiano, Rodolfo Llinás, en su libro El cerebro y el mito del yo, "el cerebro sería fundamentalmente una máquina de aprender. (2003, p. 205)

El proceso de preguntarse es fundamental para que se pueda enseñar a pensar en las ciencias sociales. En la entrevista realizada en el programa Diálogos a Rodolfo Llinás, uno de los padres de la Neurociencia, comentó que educar es esencial, porque la riqueza más grande de un país es su gente, y se refirió a Colombia y planteó que no educar por lo productivo en términos económicos sino por el placer de entender, y producir conocimiento. (Canal Capital, 2012) 
Este planteamiento de Llinás trae a la memoria la crítica que hizo a la educación de Latinoamérica Paulo Freire (2000) al referir que se privilegia una educación bancaria y no una educación crítica, cuando solo reproducimos información y no proponemos en el aula la discusión, la puesta en escena y la contextualización de la información.

La relación entre lo acumulado en el proceso informativo y lo leído por nuestro cerebro da como resultado una serie de procesos sustanciales para el desarrollo cognitivo de nuestros estudiantes y docentes, como por ejemplo el análisis, esencial para enriquecer los procesos de rastreo de información, y que, más allá de la misma acumulación de datos, es una posibilidad inconmensurable para generar procesos de investigación sustentados y críticos.

La doctora Silvia Renata Figiacone (2012), Psicopedagoga y Doctora en Psicología, en su conferencia sobre Neurociencia y Educación plantea que "para aprender hay que tener una experiencia de pensar, hablar, entender". Al respecto existe una gran responsabilidad del maestro sobre su papel en la enseñanza y el proceso de aprendizaje mediado por la internet, para direccionar la búsqueda de información orientando al estudiante en la riqueza de la autopista electrónica. Esto lleva a pensar la docencia y su práctica a un cambio en los procesos de enseñanza-aprendizaje; al respecto hay que ver que las aulas no han cambiado en muchos de los países, incluido el nuestro; sin embargo, en el mundo hay aulas que sí han cambiado y una de ellas es el aula de las preguntas inteligentes y en contexto.

Si como docentes no logramos comprender la responsabilidad que tenemos con la cognición y la producción de conocimiento, estaremos condenados a anquilosarnos ante el paso avanzado de la tecnología; crónica de una muerte anunciada que se inserta en los pasos acelerados de la evolución tecnológica, entre otras razones, por las malas prácticas pedagógicas utilizadas por los docentes que, en muchos casos, han permitido la elaboración y aprobación de trabajos que solo son un cúmulo de datos estériles e insustanciales.

Hoy es prioritario, tanto en estudiantes como en docentes, una buena utilización de la internet, mayor exigencia y revisión de las relaciones conceptuales que se tejen durante los procesos académicos, así como mayor exigencia y elaboración en las argumentaciones; de tal manera que se incentive en nuestros estudiantes el interés por la lecto-escritura, y que podamos pasar de una producción de contenidos a aprendizajes significativos que transforman los sujetos y sus formas de relacionamiento.

Como docente, debo confesar que cuando pensé en escribir sobre esta temática - el uso de recursos en la autopista electrónica, específicamente para los procesos de investigación en las ciencias sociales aplicadas -, lo hice con especial diligencia, porque como profesora universitaria me preocupan 


\section{Contexto Garcia, G.}

los aspectos pedagógicos y metodológicos del uso de la información, y sobre todo, aquella que refiere una procedencia ciberespacial, pues, considero que esta última es de vital importancia para que los estudiantes, de manera reflexiva y critica, hagan un uso adecuado a todos los recursos de información que provienen del mundo de la virtualidad, máxime cuando las nuevas generaciones son los ciudadanos de la información y la comunicación, que usan el mundo virtual y sus recursos para resolver sus interrogantes sobre diferentes problemáticas de la vida cotidiana, y no ciudadanos digitales como en el pasado reciente.

Por tanto, existe una gran responsabilidad del sistema educativo, y más específicamente del maestro, en la formación del estudiante y en la alfabetización del uso de recursos electrónicos en los procesos de aprendizaje de la investigación en el aula; el profesor, por ninguna razón, puede perder el manejo del currículo ni puede dejar de lado los principios didácticos que rigen tal proceso.

Las nuevas formas de ver el mundo, a partir de la globalización, el creciente uso de elementos tecnológicos que han facilitado la comunicación sugieren unas nuevas dinámicas de enseñanza-aprendizaje que modifiquen las estructuras pedagógicas, curriculares y didácticas entre el profesor y el estudiante, pues los profesores - por lo menos de la generación a la que yo pertenezco - nacieron, crecieron y se han habituado a las dinámicas del mundo a partir de las necesidades inmediatas, pero no han estado mediados por la tecnología la mayor parte de su vida; mientras que nuestros estudiantes han estado inmersos en tal dinámica desde su nacimiento, y ello constituye una brecha generacional que se debe disminuir a partir de la contextualización y la comprensión de las diferentes subjetividades.

Nuestro estudiantes mueven la industria del consumo, conversan con sus amigos, en micro-milésimas de segundo obtienen respuestas a sus interrogantes vía web; se mantienen informados, pues sus conversaciones van desde la moda, la política y la cultura hasta los aspectos más banales que puedan existir. Mis estudiantes piensan que los libros de las bibliotecas, los periódicos y las revistas deben transformarse para entrar en su era, en sus necesidades, porque a ellos les interesa una información ágil y altamente variada, en el tiempo del que disponen, pues la tecnología los ha acercado a tantos mundos, a tantas personas que no les basta la retórica de la usanza literaria y paciente de otrora.

Platón y Aristóteles tuvieron la oportunidad de nacer en una época en la que el lenguaje estaba mediado sólo por la cercanía y la palabra oral o escrita, sus discípulos estaban a la vuelta de la mesa para compartir con ellos cualquier tipo de reflexión; parodiando una frase bíblica, la palabra se hizo carne en ellos. Para la generación actual la palabra no se hizo carne sino que está en los medios masivos de comunicación, en las personas que se mueven a través 
de la web, en las redes sociales, en los chats, en los foros, en los correos, en una cantidad de elementos que se escapan a las lógicas que como docentes de otra generación no logramos comprender, y a veces ni siquiera nombrar.

En las redes sociales se comparte conocimiento; los teléfonos inteligentes, las tabletas y los portátiles se usan hoy para leer, y no los libros como pensaríamos; hoy la mayoría de las personas caminamos con libros y revistas, no en las mochilas sino en los procesadores. Nuestros jóvenes de hoy, lejos de las plumas y los bolígrafos, escriben; no manejan libros de papel, pero leen; no usan la palabra para conversar mirándonos a los ojos, pero dialogan entre ellos; son analíticos y reflexivos, y lo más complejo de comprender entre nosotros es que frente al uso de la web son más ágiles y dinámicos que nosotros, incluso plantean que sería un desperdicio no saber usar los medios. ${ }^{6}$

Los docentes tenemos que comprender que se ha modificado la cultura y nuestras formas de vivir; por tanto, aquellos profesores que aún habitan las universidades y que no han aprendido a dialogar en estos nuevos lenguajes, ven vacíos y dificultades en los estudiantes, no son capaces de canalizar sus destrezas y desperdician sus capacidades, ininteligibles para nosotros. Ahora bien, tales docentes deben hacer una reflexión juiciosa y sentida, en tanto su resistencia al cambio no les permite repensarse en los nuevos contextos de enseñanza-aprendizaje, los mismos que reclaman constantemente sus estudiantes.

A propósito de cómo hemos ido cambiando nuestra forma de conocer el mundo, vale la pena traer a colación algunos teóricos de la corriente del determinismo tecnológico, corriente filosófica que plantea que todo acontecimiento siempre tiene una relación de causa-efecto, y eso es lo que he tratado de trabajar en el discurso. Al pararme de manera reflexiva en los planteamientos de algunos de estos autores, quiero nuevamente usar la metáfora como punto en comunión con ellos.

Me quiero referir al geógrafo alemán Friedrich Ratzel, considerado como el fundador de la antropogeografía, quien perteneció a los denominados clásicos de la geopolítica. En principio su teoría se denominó biologismo social, y más adelante desarrolló la teoría del espacio vital, la misma que utilizó la Alemania nazi para su proceso de expansión territorial.

[una] nación podía sobrevivir cuando dispusiera del espacio suficiente para satisfacer sus propias necesidades, disputándolo, a través de la lucha, con otros estados. El espacio vital, por tanto, nace de la lucha entre las naciones, y la victoria conlleva el derecho a disfrutar del territorio que se necesita para poder subsistir. (Mestre, 2012)

6. El aula de clase se modifica a diario, según las necesidades del proceso académico, y es allí donde estudiantes y docentes deben lograr entendimientos en la relación, enseñanza-aprendizaje-evaluación. 


\section{Contexto}

Sin hacer apología al nazismo como ideología ni mucho menos, me interesa rescatar el concepto de "espacio vital para sobrevivir" en relación con el uso que hacen las generaciones de hoy del mundo virtual; metafóricamente, podríamos afirmar que este es su espacio vital, debido a que por allí no solo camina la información sino la comunicación y sus relaciones con el mundo. ${ }^{7}$

En conclusión, la teoría del espacio vital de Friedrich Ratzel, según la cual existe una relación causa-efecto entre los rasgos físicos de la geografía, como espacio y ambiente, puede contribuir a inferir que con la globalización, los espacio geopolíticos se han modificado, puesto que hoy existe una gran influencia de la tecnología sobre tales, pues este determinismo tecnológico que se expande a todas las esferas del ambiente cultural de los seres humanos, está influenciando las formas evolutivas de la internet, las comunicaciones y las relaciones comunicativas de las masas sociales.

Hoy todo está en "la aldea global", término acuñado por Marshall McLuhan, considerado un visionario y profeta de la comunicación del siglo XX. Su proyección pública contribuyó a la divulgación de la reflexión sobre los medios como fenómeno central de la modernidad, sus reflexiones e intuiciones, sus provocaciones y extravagancias intelectuales estimularon el debate académico y sacaron al espacio público la importancia adquirida por las nuevas extensiones tecnológicas de la comunicación y de los medios. (Infoamérica, s.f.)

El pensamiento de McLuhan ha pasado la frontera del tiempo y de quienes han controvertido sus teorías, quizás porque la misma historia ratificó la influencia de la tecnología en diferentes ámbitos de la vida cultural de las sociedades. Sus posiciones teóricas se incluyen dentro de la corriente del determinismo tecnológico, pues, a partir de sus conceptualizaciones la tecnología es vista como una extensión ortopédica del sistema sensorialbiológico, de gran efecto sobre las comunicaciones.

La educación no solo tiene la tarea de ayudar a entender de manera crítica el uso de la información en el proceso de conocer sino que debe ser más crítica y reflexiva sobre el determinismo tecnológico, para que éste, de verdad pueda aportar a la construcción de sociedad y de sujetos. Podemos usar las herramientas de la virtualidad con alto sentido crítico para rastrear información que aporta a la comprensión de nuestros procesos investigativos, por tanto el uso del recurso tecnológico, dentro y fuera del aula, debe ser trasversal al interés del maestro y de sus estudiantes.

7. Este espacio vital, en lo que se ha convertido el mundo de la virtualidad, es el mundo más politizado de hoy, basta con leer los titulares de prensa sobre cómo se descubren secretos que debieron permanecer guardados cual momia del pasado, y cómo también, con ayuda de las redes sociales, se derrocan gobiernos y se eleva la comunicación al espacio sin fronteras, donde la participación es un poco más libre; claro que todo esto ha llevado a que los Estados totalitarios comiencen a imponer controles para que la información no fluya como lo pensaron y piensan quienes, con espíritu libertario, crearon el mundo del ciberespacio. 
El establecer los parámetros para una buena relación conceptual y no una mera acumulación de información, priorizando comparaciones, jerarquizaciones, análisis, opiniones y otras relaciones como condiciones de homogeneización de estilo, que apunten a evitar el copiado automático de textos, permite mejorar la calidad académica de nuestras instituciones y por ende la calidad profesional de nuestros estudiantes.

Este punto tiene una gran relación con los argumentos enunciados al comienzo del artículo, donde enfaticé en la responsabilidad que tenemos de producir conocimiento, y nuestros estudiantes deben hacer uso de todas las herramientas que la lingüística y la hermenéutica les brindan, además de una gran dosis de manejo de la redacción que les permita promover la vinculación de conceptos, la comparación de información con ideas previas y opiniones personales para propiciar el aprendizaje significativo.

Como docentes, utilizar algunas de las posibilidades que tenemos en el servicio de la internet es acercar a nuestros estudiantes a nuevas problemáticas y nuevas formas de ver el mundo, es canalizar sus iniciativas e inquietudes hacia la creación de elementos positivos y significativos de su aprendizaje. Es responsabilidad de la academia adecuarse a los tiempos que corren y evitar que las prácticas descontextualizadas lleven a la universidad al anacronismo.

La idea es ante todo, buscar provecho de la utilización de las TIC, optimizando el sistema que se genera entre el estudiante y los buscadores de información académica que hacen posible el acceso al material en la red, además favorecer, a través de la creación de un contexto adecuado, la adquisición de habilidades específicas respecto de la selección, organización y comprensión de la información; habilidades que incluso podrían ser potencialmente transferibles a otros contextos educacionales y formativos, aun careciendo del recuso tecnológico.

En síntesis se sugiere generar las condiciones adecuadas y posibles para optimizar los efectos obtenidos al operar con las TIC, además de buscar un residuo cognitivo transferible a otros contextos. Hay que mostrarle al estudiante que incluso en la red hay formas de lograr el acercamiento a otras fuentes de información más actualizadas y coherentes con sus criterios de búsqueda, como es el caso de las bases de datos, por lo menos más coherentes que las que puede encontrar en los buscadores tradicionales de su preferencia, los mismos que como docentes satanizamos en las aulas de clase.

\section{La imposibilidad de concluir: lo que hace ruido entre profesores y estudiantes}

Muchos son los ruidos que acompañan la posmodernidad, uno de ellos es la agilidad de la ciberautopista, de los procesos de información, y hasta la falta en algunos casos, de selección de lo que se lee allí, y su uso constante por 


\section{Contexto Garcia,,}

las nuevas generaciones. Estos aspectos hicieron reflexionar a teóricos como Jean Baudrillard (1983) y Zygmunt Bauman (2004 y 2005). Baudrillard cuestiona la realidad virtual, pues considera que esta nos aleja de la historia, del silencio, también por la carencia de objetos que nos generen vínculo. Por esta razón, vale la pena, a la hora de utilizar la ciberautopista, que esta no sea solo un medio sin transcendencia sino la herramienta que posibilite una serie de relaciones en torno al objeto, para que maestros y estudiantes alcancen niveles importantes en la investigación en el aula a la hora de usar con pertinencia la internet en los rastreos de bibliografía. algunos de esos ruidos sonoros tienen que ver con frases como las que mencionaré a continuación, y he escuchado de mis colegas:

- Que los estudiantes todo lo pegan de internet.

- Que no leen.

- Que no son originales, que no piensan.

- Que no escriben.

- No me gusta la internet.

- No creo importante comunicarme por el correo.

- No tengo espacio virtual para comunicar la información a los estudiantes.

- Qué pereza leer esos trabajos.

- No pongo trabajos para no perder el tiempo.

- Yo solo hago evaluaciones.

Estos ruidos hacen mucho daño al trabajo en el aula; el compromiso de nosotros los docentes es motivar constantemente al estudiante para exigirse en la construcción de conocimiento, en el uso del lenguaje y de la palabra, y hacer un llamado a repensar cómo concibe Colombia la educación; develar el lugar de importancia en su desarrollo y enfrentar el papel del currículo y las didácticas en el aula.

Para Silvia Renata Figiacone (2012) el pensamiento crítico en el aula, a través de la autorreflexión de maestros y estudiantes, genera un clima de comunicación, y así se evita que los alumnos repitan solo lo que el maestro enseña.

Uno de los planteamientos importantes en el aula es que maestros y estudiantes lean, lo mencionan pensadores críticos como Paulo Freire (2000) y Henri Giroux (2004), porque leer propicia una conversación con la historia y los acontecimientos que se suceden en el mundo y motiva la creatividad en los sujetos; ellos no plantean dónde leer, por eso volvemos nuevamente a sugerir el uso de la información proveniente de la web para leer, porque los mayores cambios hay que darlos en la educación como sistema y en las formas de enseñar y aprender; por ello hay que traer a colación a otros pensadores como Gabriel García Márquez, que sugieren la posibilidad de pensar una educación diferente, como la que propuso el nobel en un país 
para los niños en el texto "Colombia al filo de la oportunidad":

Una educación desde la cuna hasta la tumba, inconforme y reflexiva, que nos inspire un nuevo modo de pensar y nos incite a descubrir quiénes somos en una sociedad que se quiera más a sí misma. Que aproveche al máximo nuestra creatividad inagotable [...]. (1996, p. 56)

De Rodolfo Llinás, el neurocirujano, investigador y científico colombiano, se debe rescatar el que el maestro debe creer en las preguntas y debe estar preparado para responder desde el contexto. En la entrevista realizada por Canal Capital (2012) dijo que "el maestro debe asombrar con la pregunta en contexto, porque sin contexto no hago nada"; el estudiante debe hacer exploración y juicio crítico, y debe integrar los conocimientos previos al contexto que está estudiando.

Debe haber diversión o como diría el científico colombiano Raúl Cuero: "Hay que aprender a disfrutar todo lo que se hace. Uno tiene que estar preparado para tomar ventaja de la experiencia que está buscando" (Politécnico Colombiano Jaime Isaza Cadavid, 2012). Por eso el maestro debe entender el mundo de sus estudiantes o, como diría Figiacone (2012), "lo que socialmente es relevante para los alumnos, no lo debemos negar, porque si no perdemos". La internet es socialmente relevante para las generaciones de hoy, y ello hace necesario su uso en el aula, mediada por las formas que el maestro construya allí con su estudiantes.

Jorge Reynolds, científico colombiano inventor del marca pasos, se refiere a varias de las problemáticas del futuro, a la trascendencia que tiene la información para la innovación; plantea la importancia de la autoconciencia, reconoce que Colombia tiene su mayor riqueza en las gentes que la habitan y que por lo mismo cada uno debe conocer las fortalezas de sí mismo y de los demás con los cuales comparte la información. Además, que es importante hacer interdisciplinariedad porque cada disciplina tiene algo que aportar al conocimiento, y que la "internet plantea un mundo de posibilidades que solo hasta hoy comenzamos a aprovechar". (Innovadores de América, 2011)

Es relevante la emoción en el aula. Enseñar a tolerar la frustración es una novedad estratégica que no se debe dejar de lado, porque en el aprendizaje el estudiante debe aprender y sentir seguridad de lo que conoce. La vitalidad del rastreo bibliográfico radica en romper el paradigma de la biblioteca tradicional, de textos anaquelados, donde el logro era visto desde el momento en que la gente aprendía a leer y a comprender lo que se leía. Hoy con la autopista electrónica, en la medida en que hemos comprendido la importancia de crear cultura informacional, el reto es no solo buscar que cada vez haya más recursos, y sean asequibles a todas las personas, sino buscar los medios y las metodologías para que las personas puedan visualizar esa vitalidad en la calidad de la información que leen, en la cultura informacional y en la alfabetización digital más allá de la "idea de 


\section{Contekto}

la instrucción bibliográfica o la formación de usuarios para el uso de los recursos de la biblioteca, incluyendo Opac's, bases de datos, entre otros". (Hernández \& García, s.f., p. 2)

Desde finales del Siglo XIX, la sociedad ha venido generando información, que ha evolucionado gracias a la aparición de los medios digitales. Este aspecto transformó el quehacer de la biblioteca, y hoy ésta es un factor importante en la intermediación cultural al proporcionar recursos de información que se articulan en lo cotidiano con la necesidad de construir conocimiento. Por eso surge la investigación como un proceso constante de hacer el saber, de estar frente a una verdad; es decir, que lo dicho de un hecho o acontecimiento corresponde efectivamente al hecho o acontecimiento mismo. Para que estas premisas se cumplan se necesita que los universitarios y los maestros asumamos una actitud responsable ante la investigación y convenzamos a nuestros estudiantes, no con verdades absolutas sino con plena convicción de que el conocimiento hace parte de la vida, y que como tal debe pensarse en ella.

La vitalidad del rastreo bibliográfico, título de este trabajo reflexivo, cobra sentido en la medida en que, como maestros, nos convencemos de que cuando realizamos el rastreo de la información como aporte a nuestros procesos de investigación o formativos dentro de las aulas de clase, tal proceso nos exige estar a la altura del momento, ser conscientes de nuestro contexto, de rápida des-usanza de los textos anaquelados en las bibliotecas, al uso del texto que bulle por las calles congestionadas de la autopista electrónica, y que por ello se hacen necesarias, de manera estratégica, la exploración y evaluación del material académico disponible en línea, tarea que exige de los maestros y estudiantes responsabilidad a la hora de abordar los textos electrónicos.

\section{Referencias bibliográficas}

Baudrillard, J. (1983). Las estrategia fatales. Recuperado de http://p33rz. p3.funpic.org/biblioteca/Baudrillard,\%20Jean/6906264-BaudrillardJean-Las-estrategias-fatales.pdf

Bauman, Z. (2004). Modernidad líquida. Recuperado de http:// catedraepistemologia.files.wordpress.com/2009/05/modernidadliquida.pdf

Bauman, Z. (2005). Amor Liquido. Acerca de la fragilidad de los vínculos humanos. Madrid: FCE.

Canal Capital. (2012, 26 de diciembre). Rodolfo Llinás, padre de la neurociencia [video]. Diálogos. Recuperado de http://www.youtube. $\mathrm{com} /$ watch?v=JuraE2biyGE 
Figiacone, D. (2012, 15 de junio). Neurociencia y educación. Entrevista (Marín TV, Entrevistador) [video]. Recuperado de http://www. youtube.com/watch?v=elFvwyCWCzI

Freire, P. (2000). Pedagogía del oprimido. México: Siglo XXI Editores.

Friedman, L. (2013, 10 de Febrero). El espectacular ascenso de la clase media virtual. la nacion.com.ar. Recuperado de http://www.lanacion. com.ar/1553047-el-espectacular-ascenso-de-la-clase-media-virtual

Friedman, L. (2014, 22 de febrero). How to get a Job at Google. The New Yok Times. Recuperado de http://www.nytimes.com/2014/02/23/ opinion/sunday/friedman-how-to-get-a-job-at-google.html?smid=plshare

García-Márquez, G. (1996). Por un país al alcance de los niños. Bogotá: Tercer Mundo Editores.

Gates, B. (1995). Camino al futuro. Bogotá: McGrawHill.

Giroux, H. (2004). Teoría y resistencia en educación. (6a . ed.). México: Siglo XXI Editores. Recuperado de http://books.google.es/books?h $\mathrm{l}=\mathrm{es} \& \mathrm{lr}=\& \mathrm{id}=5 \mathrm{c} 2 \mathrm{eGkU} 9 \mathrm{HV} 8 \mathrm{C} \& \mathrm{oi}=\mathrm{fnd} \& \mathrm{pg}=\mathrm{PA} 9 \& \mathrm{dq}=$ giroux \&ots $=6$ PkiCPIKTM\&sig=buYu1U_151XcMM07ktUTKQv98NU\#v=on epage $\& \mathrm{q}=$ giroux $\& \mathrm{f}=$ false

Hernández, T. \& García, M. (s.f.). Los retos de la alfabetización informacional en las bibliotecas: guía para superar la brecha entre nativos e inmigrantes digitales. Prisma.com., 13. Recuperado de http:// eprints.ucm.es/12139/1/retos_alfin_biblioteca.pdf

Infoamérica. (s.f.). Marshall McLuhan (1911-1980). infoamerica.org. Recuperado de http://www.infoamerica.org/teoria/mcluhan1.htm

Innnovadores de América. (2011, 19 de diciembre). Conferencia de Jorge Reynolds [video]. Recuperado de http://www.youtube.com/ watch? $\mathrm{v}=\mathrm{rx} 5 \mathrm{SMRXSFl} 4$

Llinás, R. (2003). El cerebro y el mito del yo. Bogota: Norma.

Mestre, J. (2012, 14 de abril). El concepto de espacio vital para los nazis. suite101.net. Recuperado de http://suite101.net/article/el-conceptode-espacio-vital-para-los-nazis-a78807 


\section{Contexto}

Pérez, C. (2003). Shakespeare como filosofía. Mar Oceana, 14-15. Recuperado de http://ddfv.ufv.es/bitstream/handle/10641/772/ Shakespeare $\% 20$ como $\% 20$ filosof $\%$ C3\%ADa.pdf? sequence $=1$

Politécnico Colombiano Jaime Isaza Cadavid. (2012, noviembre). El científico Raúl Cuero. Invitado de honor.

\section{Para citar este artículo:}

García, G. (2014). Los retos de la ciberautopista electrónica en el mundo de la investigación. En-Contexto, 2, 229-244. 